\title{
The influence of CYP 2 C19*2 polymorphism on platelet function testing during single antiplatelet treatment with clopidogrel
}

\author{
Alf-Aage R Pettersen ${ }^{1 *}$, Harald Arnesen ${ }^{1,2}$, Trine B Opstad ${ }^{1}$, Ingebjorg Seljeflot ${ }^{1,2}$
}

\begin{abstract}
Background: Different platelet function tests can be used to evaluate the degree of achieved platelet inhibition in patients treated with clopidogrel. The presence of CYP 2C19*2 polymorphism can reduce the formation of the active metabolite of clopidogrel, resulting in less platelet inhibition.

Patients and Methods: Patients with symptomatic coronary artery disease, all on chronic single aspirin treatment were randomized to continue on aspirin or change to clopidogrel. In 219 randomly selected clopidogrel treated patients, platelet reactivity was evaluated by VASP-PRI determination and by use of VerifyNow P2Y12-PRU. The CYP $2 \mathrm{C} 19^{*} 2 \mathrm{G} / \mathrm{A}$ polymorphism was further determined.

Results: The total frequency of clopidogrel resistance was $29.0 \%$ by VASP-PRI and $31.6 \%$ by VerifyNow-PRU. The number of patients being hetero- and homozygous combined for the CYP 2C19*2 polymorphism (GA/AA) was 64 (29\%). Platelet reactivity was significantly higher in patients with the polymorphism compared to wild-type patients (GG). VASP-PRI was 50.9\% (SD19) in patients having the polymorphism compared to 38.3\% (SD21) in patients with the GG genotype $(p=0.001$ ). Correspondingly, the mean PRU was 165 (SD67) compared to 124 (SD69) $(p<0.001)$. The frequency of clopidogrel resistance in patients with the polymorphism was 32\% compared to $16 \%$ in wild-type patients when defined by VASP-PRI ( $p=0.006)$. When defined by PRU (VerifyNow), the corresponding frequencies were $53 \%$ and $22 \%(p<0.001)$.
\end{abstract}

Conclusions: Clopidogrel treated patients with the CYP 2C19*2 polymorphism have significantly increased platelet reactivity compared to patients with the wild-type, evaluated with the VASP determination, and even more pronounced with the VerifyNow P2Y12 method.

Trial Registration: ClinicalTrials.gov: NCT00222261

\section{Background}

Antiplatelet therapy is widely used in patients with a high risk of atherothrombosis and has become a cornerstone in treatment of coronary artery disease (CAD) [1]. Aspirin has been the primary choice for decades, whereas the benefit of adding clopidogrel in high-risk patients has been demonstrated in several trials $[2,3]$. Despite improvement in antiplatelet regimens, patients on-treatment run a considerable risk for new thrombotic events [4].

\footnotetext{
* Correspondence: alfaage@online.no

${ }^{1}$ Center for Clinical Heart Research. Department of Cardiology, Oslo

University Hospital, Ullevaal, Oslo, Norway

Full list of author information is available at the end of the article
}

Although clinical benefit has been shown with clopidogrel, interindividual variation of platelet inhibition has been focused as an important explanation of insufficient platelet inhibition that might be a risk factor for new thrombotic events. The term "clopidogrel resistance" has been used to describe this phenomenon [5-7].

The in vivo transformation of clopidogrel to it's active metabolite is an important and critical step for the drug's antiplatelet effect. Clopidogrel is metabolized to the active metabolite that inhibits the ADP receptor P2Y12, and thereby inhibiting the ADP mediated platelet activation. This metabolization is dependent on the hepatic cytochrome P450 isoenzymes like CYP2C19, CYP1A2, CYP2B6, CYP2C9 and CYP3A4. Clopidogrel response

\section{C) Biomed Central}


variability is, to a large extent, explained by the extent of formation of the active metabolite of the drug [8].

Today, at least 25 single nucleotide polymorphisms (SNPs) in the gene coding for CYP2C19 have been described, and the "loss-of-function" allele CYP2C19"2 in exon 5, the most common and most studied polymorphism, has been shown to give a significant reduction in serum concentration of the active metabolite of clopidogrel and also to reduce inhibition of platelet aggregation [9-13].

Different platelet function tests have been used to evaluate the degree of achieved platelet inhibition in patients treated with clopidogrel. Light transmission aggregometry with ADP as an agonist, is the most evaluated and used method, but the test is time consuming and not practical for routine use. A new point-of-care system is the "VerifyNow" method in which the results have been shown to predict clinical outcome $[14,15]$. Determination of "Vasodilator Stimulated Phosphoprotein" (VASP) has been considered to be the most specific test for the degree of inhibition of the platelet P2Y12 receptor. Thus, this test has been considered to give the best answer on the platelet inhibition achieved by clopidogrel $[16,17]$.

Several studies have reported on the platelet inhibiting effect of clopidogrel in combination with aspirin by use of different laboratory methods and cut-off values $[7,18,19]$. The aim of the present investigation was to study the frequency of resistance to single clopidogrel treatment in stable CAD patients by use of both the VerifyNow and the VASP methods. Further, we wanted to study the influence of the "loss-of-function" polymorphism, CYP2C19*2, on the functional assays.

\section{Materials and methods \\ Study population}

This is a sub-study of the Aspirin and Clopidogrel nonresponsiveness clinical Endpoint Trial (ASCET) in which patients were enrolled between March 2003 and July 2008 [20]. The ASCET trial is a randomized, single center, open labeled clinical trial where 1001 patients with stable symptomatic CAD, all on chronic aspirin treatment, were randomized to either continued treatment with aspirin $160 \mathrm{mg} / \mathrm{d}$ or to clopidogrel $75 \mathrm{mg} / \mathrm{d}$ with a follow-up for two years. The study was approved by the regional ethics committee, and patients were included after giving their written informed consent.

In the present sub-study, all patients randomized to clopidogrel were consecutively included from October 2005 to June $2008(\mathrm{n}=219)$.

In addition, patients from the ASCET cohort being on aspirin $(n=120)$, were included to identify the cut-off level for responsiveness with the VerifyNow- and VASPmethods. Recording of baseline characteristics were based on the patients medical files and the medical interview. Patients were classified as diabetics when previous diagnosed and treated diabetes or when presenting with fasting plasma glucose $>7.0 \mathrm{mmol} / \mathrm{L}$. Hypertension was defined as previous diagnosed and treated hypertension. Recording of smoking habits were based on patient interviews. Previous smokers (smoking cessation more than 3 months ago) were classified as non-smokers. Current medication and body mass index (BMI) were recorded by patient interviews and by clinical examinations.

\section{Blood sampling}

One month after randomization to clopidogrel, blood samples were drawn between 08.00 and 10.30 in fasting condition 24 hours after the last intake of medication. Compliance was assessed by interview and by a written questionnaire. Routine analyses were performed by use of conventional laboratory methods. Citrated blood (0.129 mM in dilution 1:10) was used for VASP analyses, and Vacuette tubes (Grüner Bio-One GmbH, Austria) (0.109 mM in dilution 1:10) were used for VerifyNow determination. For gene analyses, EDTA whole blood was used.

\section{VASP analysis}

VASP is an intracellular actin regulatory protein. The phosphorylation of VASP is regulated by the cyclic adenosine monophosphate cascade. The phosphorylation status of VASP correlates with P2Y12 receptor inhibition. Thus, levels of VASP phosphorylation/de-phosphorylation reflect P2Y12 inhibition/activation.

VASP was determined, within 48 hours after blood collection, by use of the PLT VASP/P2Y12 assay (Biocytex, France). The FACS Calibur System (Becton Dickinson, Plymouth, UK) was used. The results are expressed as Platelet Reactivity Index (VASP-PRI) as described by the manufacturer. The lower the VASPPRI, the higher is the biological effect of clopidogrel $[17,21,22]$. The intra assay coefficient of variation for VASP analyses was $2.3 \%$.

\section{VerifyNow-P2Y12}

VerifyNow (Accumetrics, San Diego, CA, USA) is an optically based detection device designed to measure platelet aggregation. This assay assesses the ability of activated platelets to bind fibrinogen-coated beads. In brief, the latter form mixed aggregates with stimulated platelets in whole blood in a process mediated by platelet GPIIb-IIIa receptors. ADP is incorporated to activate $\mathrm{ADP}$ receptors and prostaglandin E1 is added to reduce the non-specific contribution of the P2Y1 receptor. The instrument measures the change in light transmittance and the results are reported in Platelet Reaction Units 
(PRU). The intra assay coefficient of variation for VerifyNow analyses was $7 \%$.

\section{Determination of Cut-Off values}

We defined the cut-off levels for clopidogrel resistance as measured by VASP and VerifyNow P2Y12, as the lower 5 percentile of patients on chronic aspirin treatment $(\mathrm{n}=120)$, giving VASP-PRI $\geq 55 \%$ and PRU $\geq 170$ to be resistant.

\section{DNA isolation}

DNA was purified from EDTA whole blood on the Magna Pure LC Instrument (Roche Diagnostics GmbH, Mannheim, Germany), using MagNA Pure DNA LC isolation kit, Large Volume (Roche Diagnostics GmbH). DNA purity and quantity were tested on the NanoDrop, ND-1000 (Saveen Werner, Sweden) and DNA was kept at $-80^{\circ} \mathrm{C}$ until analysed.

\section{Genotype analysis}

The "loss-of-function" cytochrome 2C19*2 G/A polymorphism ( $r$ 4244285) was investigated. Allelic discrimination was performed by the ABI Prism 7900 HT Sequence Detection System using allele specific primers and probes included in the TaqMan Drug Metabolism Assay mix (Applied Biosystems, Foster City, CA, USA).

\section{Statistics}

Continuous variables are presented as means \pm SD and categorical variables are presented as numbers or percentages. Group comparisons were performed by Student's unpaired t-tests or Mann-Whitney U-tests when appropriate for continous variables and by the chi-square test or Fisher's exact test for categorical variables. Correlation analyses were performed by Spearmans rho. A p $<0.05$ was considered to be statistically significant. SPSS statistical software, version 18.0 (SPSS Inc., IBM, Chicago, IL, USA) was used.

\section{Results}

In Table 1, some selected clinical and laboratory characteristics of the total population $(\mathrm{n}=219)$, all caucasians, are given. Number of samples successfully analyzed for the SNP was 218, 155 for VASP and 212 for VerifyNow, respectively.

\section{Functional tests}

According to the defined cut-off values, the total frequency of clopidogrel resistance was $29 \%(n=45)$ when measured by VASP determination and $32 \%(\mathrm{n}=67)$ when measured by the VerifyNow P2Y12. The distributions of response, shown in deciles in the total population, are shown in Figures 1a and $1 \mathrm{~b}$.
Table 1 Baseline Characteristics of the Study Population

\begin{tabular}{lll}
\hline Age & (years) & $62 \pm 8.5$ \\
Male & $(\%)$ & 79 \\
Caucasian & $(\%)$ & 100 \\
SBP & $(\mathrm{mmHg})$ & $138.2 \pm 18.6$ \\
DBP & $(\mathrm{mmHg})$ & $82.1 \pm 9.2$ \\
Pulse & $(\mathrm{beats} / \mathrm{min})$ & $61.7 \pm 9.3$ \\
BMI & $\left(\mathrm{kg} / \mathrm{m}^{2}\right)$ & $27.2 \pm 3.7$ \\
Current smoking & $(\%)$ & 16 \\
History of hypertension & $(\%)$ & 58 \\
Diabetes mellitus & $(\%)$ & 11 \\
Previous PCl & $(\%)$ & 38 \\
Previous MI & $(\%)$ & 37 \\
Previous CABG & $(\%)$ & 19 \\
Total cholesterol & $(\mathrm{mmol} / \mathrm{L})$ & $4.36 \pm 0.94$ \\
LDL-cholesterol & $(\mathrm{mmol} / \mathrm{L})$ & $2.38 \pm 0.83$ \\
HDL-cholesterol & $(\mathrm{mmol} / \mathrm{L})$ & $1.34 \pm 0.36$ \\
Triglycerides & $(\mathrm{mmol} / \mathrm{L})$ & $1.51 \pm 1.12$ \\
Medication: & & \\
Aspirin & $(\%)$ & 100 \\
Clopidogrel & $(\%)$ & 0 \\
Statins & $(\%)$ & 98 \\
Betablockers & $(\%)$ & 71 \\
CCBs & $(\%)$ & 23 \\
PPls & $(\%)$ & 14 \\
\hline Demographic &
\end{tabular}

Demographic and clinical characteristics of the study population $(n=219)$. Mean values $\pm S D$ and proportions are given.

Abbreviations: SBP (systolic blood pressure), DBP (diastolic blood pressure), BMI (body mass index), $\mathrm{PCI}$ (percutaneous coronary intervention), MI (myocardial infarction), CABG (coronary arterial by-pass grafting), CCBs (Calcium Channel Blockers), PPIs (proton-pump inhibitors).

The correlation between the levels of VASP-PRI and VerifyNow-PRU was highly significant $(\mathrm{r}=0.682, \mathrm{p}<$ 0.001) (Figure 2).

Comparing the number of patients being resistant with the two methods, the concordance (agreement) was $74.5 \%(\mathrm{p}<0.001$, kappa 0.379).

\section{Platelet response as related to genotype}

The number of patients being heterozygous $(n=61)$ and homozygous $(\mathrm{n}=3)$ combined for the CYP $2 \mathrm{C} 19 * 2$ polymorphism (GA/AA), was $64(29 \%)$. There were no significant differences in any clinical characteristics between patients carrying the CYP2C19*2 polymorphism or not, except for a higher frequency of previous myocardial infarction in patients with the polymorphism (52\% vs $32 \%, \mathrm{p}=0.004)$.

Platelet reactivity was significantly higher in patients with the polymorphism (GA/AA genotypes combined) compared to wild-type patients (GG) measured by both methods. Mean VASP-PRI levels were $51 \%$ versus $38 \%$, and mean VerifyNow-PRU levels were 162 vs 121 , respectively ( $\mathrm{p}<0.001$ for both). 

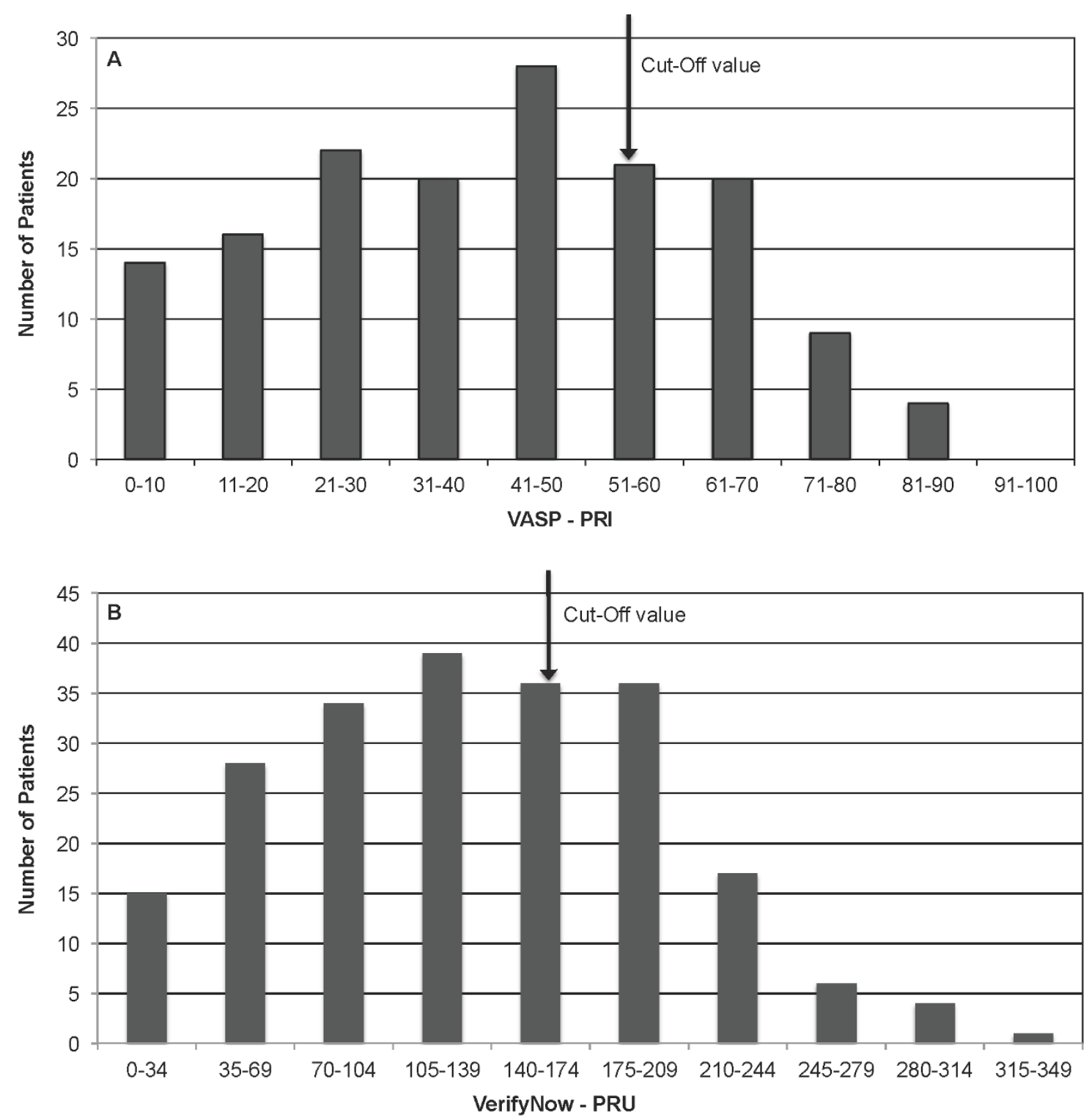

Figure 1 Frequency distribution (in deciles) of VASP-PRI (Panel a) and VerifyNow-PRU (Panel b) in patients on clopidogrel as single antiplatelet therapy. Cut-off levels $\geq 55$ and $\geq 170$, respectively, as indicated.

Correspondingly, the frequency of clopidogrel resistance in patients with the polymorphism was $46 \%$ compared to $22 \%$ in wild-type patients when defined by VASP-PRI $(\mathrm{p}=0.003)$ and $54 \%$ compared to $22 \%$ when defined by VerifyNow-PRU ( $<0.001)$ (Figure 3).

Platelet response in relevant subgroups of patients (Table 2) In the total population, there were no differences in the frequency of resistance within relevant subgroups, including use of medication, when assessed by VASPPRI. Evaluated by VerifyNow PRU, higher prevalence of resistance was found in patients with previous myocardial infarction $(\mathrm{p}=0.006)$ and in patients with BMI above median $\left(27 \mathrm{~kg} / \mathrm{m}^{2}\right)(\mathrm{p}=0.015)$. Significantly higher frequency was also observed in calcium-channel blocker (CCB) users (45\% versus $28 \%, \mathrm{p}=0.031$ ). Specifically, no differences in the frequency of non-responders were observed between patients treated with proton pump inhibitors (PPI) or not (Table 2).

\section{Discussion}

In the present study, the main findings were that patients with stable CAD on single clopidogrel treatment carrying the CYP2C19*2 A-allele, had significantly 


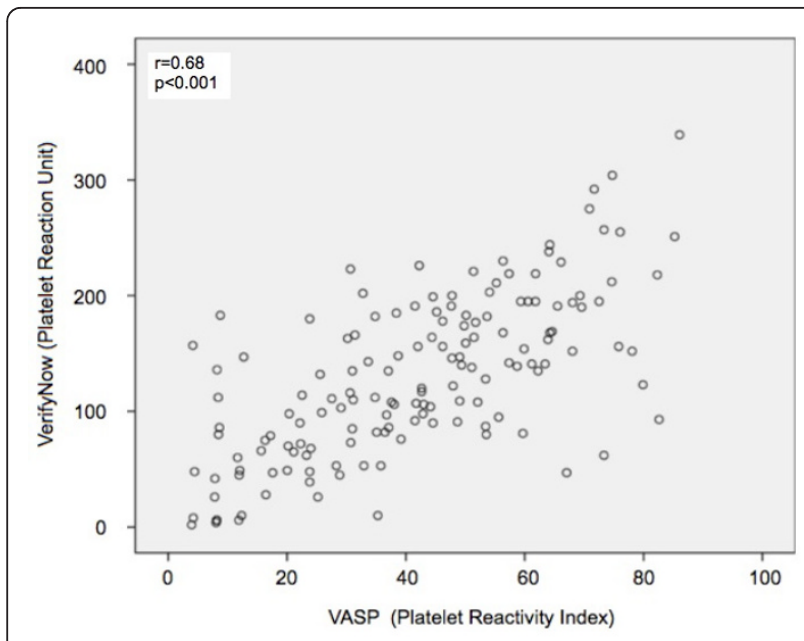

Figure $\mathbf{2}$ The correlation between platelet reactivity index, PRI, measured by VASP and platelet reaction unit, PRU, measured by the VerifyNow.

higher prevalence of clopidogrel resistance measured by both the VASP and the VerifyNow methods. The concordance between the functional methods was only fair, although statistically significant.

We found no differences in the frequencies in demographic variables in patients having the "loss-of-function" polymorphism (GA/AA) or not, except for those presenting with a previous myocardial infarction, which was significantly more prevalent in patients with the A-allele. Whether this polymorphism per se increases the risk for atherothrombosis in clopidogrel-naive patients remains to be seen.

The presence of the "loss-of function" allele CYP2C19*2 is the most frequent and also the most studied polymorphism among the SNPs in the gene. It is reported that 25-30 percent of the US population is heterozygous while 3-4 percent is homozygous with no corresponding enzymatic

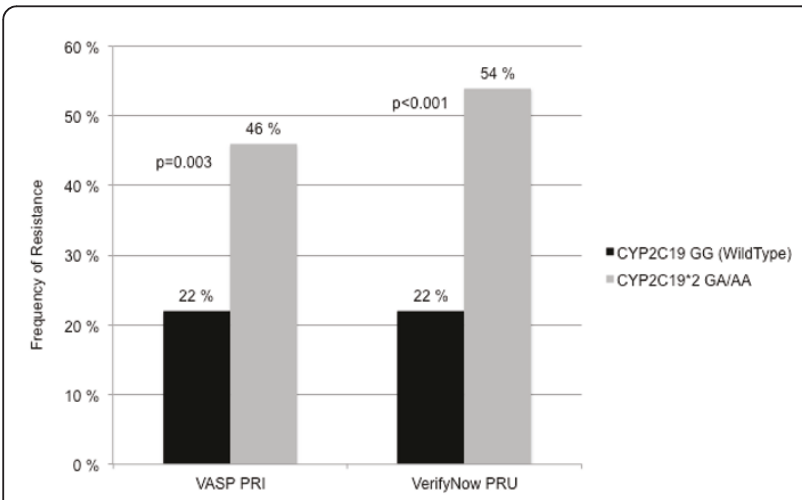

Figure 3 The frequencies of clopidogrel resistance in patients with and without the CYP2C19*2 A-allele, as determined by VASP-PRI and VerifyNow PRU activity, and similar prevalence of the SNP has been reported in a European population [12,13]. The frequency of this polymorphism in our study (29\%) is in accordance with these reports.

Even though most of the other SNPs are rare, more studies are needed to elucidate the role of the less known polymorphisms of CYP2C19. It has recently been reported that carriers of $\mathrm{CYP} 2 \mathrm{C} 19 * 3 \mathrm{~A}$-alleles, in addition to CYP2C19*2 A-alleles, have an increased risk for acute stent thrombosis [23]. One study indicates that there might be ethnical differences, and the "loss-of-function" CYP2C19*3 A-allele has been reported to be more frequent in an Asian than in US populations [24]. Clopidogrel treated patients carrying the CYP2C19*2 A-allele have been shown to have an increased risk for recurrent ischemic events $[16,25,26]$. On the contrary, the CYP2C19*17 has been associated with enhanced expression and enzymatic activity in the CYP2C19, representing a "gain-of-function" allele that might increase the risk of bleeding during clopidogrel treatment [12,27].

Several reports on platelet function testing in patients on clopidogrel treatment have shown large response variability and also an association to increased risk for recurrent ischemic events $[4,10,11]$. The clopidogrel response variability is mostly dependent on the extent of formation of the active metabolite in the hepatic CYPsystem, although other mechanisms like intestinal absorbtion and platelet turnover may also play a role [12,28,29].

Determination of clopidogrel resistance as measured by both VASP-PRI and VerifyNow P2Y12 methods has been shown to predict clinical outcome [14-17]. However, there is still a need for standardization on how to test patients and how to define the cut-off levels. There are reports using cut-off values from 50 to $70 \%$ using the VASP-PRI method and from 162 to 235 units using the VerifyNow-PRU. We defined the cut-off values based on the lower 5 percentile in the ASCET study population, in which all are CAD patients, while on aspirin $160 \mathrm{mg} / \mathrm{d}$. With these cut-off levels, we found that $29 \%$ were defined as resistant with the VASP method and 32\% with the VerifyNow P2Y12 method. This correlates well with previous reports $[22,30]$. By using patients with documented CAD to estimate the cut-off value, we might achieve a lower cut-off value with a higher number of clopidogrel resistant patients because the control patients might have more activated platelets than healthy individuals. Controls from the same study population might therefore give a relevant picture.

The correlation between the two tests was highly significant, but the agreement between the tests was only fair (kappa 0.379). Using cut-off values of 70\% (VASPPRI) and 235 units (VerifyNow-PRU), the frequencies of 
Table 2 Frequencies of clopidogrel resistance in subgroups

\begin{tabular}{|c|c|c|c|c|c|}
\hline & & VASP-PRI Resistant $(n=45)$ & $p_{\text {-value }}{ }^{1}$ & VerifyNow-PRU Resistant $(n=67)$ & p-value ${ }^{2}$ \\
\hline \multirow[t]{2}{*}{ Diabetes } & Yes & $8(31 \%)$ & & $14(45 \%)$ & \\
\hline & No & $37(29 \%)$ & .831 & $53(29 \%)$ & .079 \\
\hline \multirow[t]{2}{*}{ Smoking } & Yes & 7 (29\%) & & $10(30 \%)$ & \\
\hline & No & $38(29 \%)$ & .987 & $57(32 \%)$ & .861 \\
\hline \multirow[t]{2}{*}{ Hypertension } & Yes & $27(29 \%)$ & & $42(35 \%)$ & \\
\hline & No & $18(29 \%)$ & 1.000 & $25(27 \%)$ & .262 \\
\hline \multirow[t]{2}{*}{ Previous Ml } & Yes & $19(33 \%)$ & & $34(43 \%)$ & \\
\hline & No & $26(27 \%)$ & .429 & $33(25 \%)$ & .006 \\
\hline \multirow[t]{2}{*}{ Statins } & Yes & $44(29 \%)$ & & $63(30 \%)$ & \\
\hline & No & $1(25 \%)$ & .857 & $4(80 \%)$ & .180 \\
\hline \multirow[t]{2}{*}{ CCBs } & Yes & $10(30 \%)$ & & $21(45 \%)$ & \\
\hline & No & $35(29 \%)$ & .856 & $46(28 \%)$ & .031 \\
\hline \multirow[t]{2}{*}{ PPIs } & Yes & $9(43 \%)$ & & $7(26 \%)$ & \\
\hline & No & $36(27 \%)$ & .440 & $60(32 \%)$ & .665 \\
\hline \multirow[t]{2}{*}{$\mathrm{BMl} \geq 27(\mathrm{~kg} / \mathrm{m} 2)$} & Yes & $29(35 \%)$ & & $43(39 \%)$ & \\
\hline & No & $16(22 \%)$ & .082 & $24(24 \%)$ & .015 \\
\hline
\end{tabular}

Frequencies of clopidogrel resistance in subgroups, evaluated by VASP-PRI ( $n=45$ of 155) and VerifyNow-PRU ( $n=67$ of 212 ). Numbers (proportions) are given. Abbreviations: MI (myocardial infarction), CCB (calcium channel blockers), PPI (proton pump inhibitors), BMI (body-mass index).

$\mathrm{p}^{1}$-values refer to differences in subgroups assessed by the VASP-method, and $\mathrm{p}^{2}$-values refer to differences in subgroups assessed by the VerifyNow-method.

resistance were reduced (Figure 1). The correlation and agreement between the methods were, however, improved (data not shown). Correlation with clinical end-points will obviously be of great importance for the evaluation of cut-off values.

Patients carrying the CYP2C19*2 A-allele had significantly higher prevalence of clopidogrel resistance measured by both VASP and VerifyNow. This is in line with previous reports $[9,13]$. However, most studies have been performed with use of only one of the methods and in patients on dual antiplatelet therapy with clopidogrel and aspirin. Carrying the polymorphism increases the risk for a reduced effect of clopidogrel, but it is important to keep in mind that $22 \%$ of the patients without the polymorphism (wild-types) were resistant when determining the platelet function (with both methods) and about $50 \%$ of patients with the polymorphism were responders ( $54 \%$ of patients with VASP and 46\% with VerifyNow). Defining clopidogrel resistance with the genetic testing alone would give both a low sensitivity and specificity when identifying patients resistant to clopidogrel. Routine use of genetic testing is therefore so far not recommended [31,32]. Even though genotyping can be used to classify patients as poor or normal metabolizers, the actual platelet inhibition will be influenced by several other factors. Drug-drug interaction can alter the metabolization of clopidogrel to its active metabolite. Interaction with lipophilic statins, PPIs, calcium-channel blockers and warfarin, which all are metabolized by the CYP450, can reduce the formation of the active metabolite of clopidogrel, whereas cilostazol has been reported to increase the formation of the active metabolite [33-39]. Diverging results have been reported on the clinical relevance of the interaction between clopidogrel and PPIs. In our study, the use of PPIs did not influence the results of the platelet function tests, even in patients carrying the CYP2C19*2 A-allele. However, the number of patients using PPIs in our study was relatively low $(\mathrm{n}=31(14 \%))$.

Patients on calcium-channel-blockers, achieved less platelet inhibition, with the VerifyNow method, than patients not treated with calcium channel blockers. These findings are in accordance with previous reports, and might be due to CCB inhibition of the cytochrome P450 3A4 enzyme, giving less formation of active metabolite from clopidogrel $[38,40]$.

High BMI levels have also been shown to contribute to reduced clopidogrel response with increased platelet aggregation [41]. This is in line with our study, showing that patients with a BMI above median level had a lower degree of platelet inhibition compared to patients with BMI lower than median when measured by VerifyNow. It is not known whether there are specific mechanisms giving increased platelet aggregation in patients with a high BMI or if these findings are mainly a result of potentially confounding factors like diabetes, age and the lack of weightadjusted maintenance doses of antiplatelet drugs [42,43]. Finally, smoking might induce the CYP450 activation, giving an increased platelet inhibition from clopidogrel $[44,45]$. However, in our study, there were no differences in platelet inhibition between smokers and non-smokers.

Different results were obtained with the VerifyNow and VASP methods in relation to differences in sub-groups of 
patients. The VerifyNow (P2Y12 cartridge) is measuring platelet aggregation with ADP as agonist, while VASP determination is a more direct measure of ADP inhibition caused by the active metabolite. This is also visualized in the relatively weak agreement between the methods. It might be suggested that VerifyNow in a better way express the platelets total aggregation potential.

This may possible be in line with our finding of an increased frequency of clopidogrel resistance in patients with previous MI when tested with the VerifyNow method.

\section{Conclusions}

In the present study, patients with stable CAD on single antiplatelet treatment with clopidogrel had significantly reduced response when being carriers of the CYP 2C19*2 variant allele as compared to wild-type patients, when evaluated with the VASP method, and even more pronounced with the VerifyNow P2Y12 method. The consequences for clinical outcome are still debatable.

\begin{abstract}
Acknowledgements
The authors would like to thank medical laboratory technologists Vibeke Bratseth and Sissel Åkra for excellent technical assistance.

This work was supported by the Norwegian Council for Cardiovascular Diseases, "Ada and Hagbart Waages Humanitære og veldedige stiftelse", "Alf and Aagot Helgesens Legat" and Stein Erik Hagen Foundation for Clinical Heart Research, Oslo, Norway.
\end{abstract}

\section{Author details}

${ }^{1}$ Center for Clinical Heart Research. Department of Cardiology, Oslo University Hospital, Ullevaal, Oslo, Norway. ${ }^{2}$ Faculty of Medicine, University of Oslo, Oslo, Norway.

\section{Authors' contributions}

AAP has been the main investigator of the ASCET trial and he has contributioned to design and performance of the trial, acquisition of the clinical data, analysis and interpretation of the data. AAP has drafted the manuscript.

HA has made substantial contributions to conception, design and performance of the trial, analysis and interpretation of the data. HA has helped to draft the manuscript.

TBO has made substantial contributions to the analysis and interpretation of the data. TBO has helped to draft the manuscript.

IS has made substantial contributions to conception, design and performance of the trial, analysis and interpretation of the data. IS has helped to draft the manuscript.

\section{Competing interests}

The authors declare that they have no competing interests.

Received: 10 January 2011 Accepted: 22 March 2011

Published: 22 March 2011

\section{References}

1. Collaboration AT: Collaborative meta-analysis of randomised trials of antiplatelet therapy for prevention of death, myocardial infarction, and stroke in high risk patients. BMJ 2002, 324:71-86.

2. Yusuf S, Zhao F, Mehta SR, Chrolavicius S, Tognoni G, Fox KK: Effects of clopidogrel in addition to aspirin in patients with acute coronary syndromes without ST-segment elevation; the CURE trial. N Engl J Med 2001, 345:494-502
3. Mehta SR, Yusuf S, Peters RJ, Bertrand ME, Lewis BS, Natarajan MK, Malmberg K, Rupprecht H, Zhao F, Chrolavicius S, Copland I, Fox KA: Effects of pretreatment with clopidogrel and aspirin followed by long-term therapy in patients undergoing percutaneous coronary intervention: the PCI-CURE study. Lancet 2001, 358:527-533.

4. Eisenstein EL, Anstrom KJ, Kong DF, Shaw LK, Tuttle RH, Mark DB, Kramer JM, Harrington RA, Matchar DB, Kandzari DE, Peterson ED, Schulman KA, Califf RM: Clopidogrel use and long-term clinical outcomes after drug-eluting stent implantation. JAMA 2007, 297:159-168.

5. Serebruany VL, Steinhubl SR, Berger PB, Malinin Al, Bhatt DL, Topol EJ: Variability in platelet responsiveness to clopidogrel among 544 individuals. J Am Coll Cardiol 2005, 45:246-251.

6. Nguyen TA, Diodati JG, Pharand C: Resistance to clopidogrel: a review of the evidence. J Am Coll Cardiol 2005, 45:1157-1164.

7. Matetzky S, Shenkman B, Guetta V, Shechter M, Bienart R, Goldenberg I, Novikov I, Pres H, Savion N, Varon D, Hod H: Clopidogrel resistance is associated with increased risk of recurrent atherothrombotic events in patients with acute myocardial infarction. Circulation 2004, 109:3171-3175.

8. Frere C, Cuisset T, Morange PE, Quilici J, Camoin-Jau L, Saut N, Faille D, Lambert M, Juhan-Vague I, Bonnet JL, Alessi MC: Effect of cytochrome p450 polymorphisms on platelet reactivity after treatment with clopidogrel in acute coronary syndrome. Am J Cardiol 2008, 101:1088-1093.

9. Simon T, Verstuyft C, Mary-Krause M, Quteineh L, Drouet E, Meneveau N, Steg PG, Ferrieres J, Danchin N, Becquemont L: Genetic determinants of response to clopidogrel and cardiovascular events. N Engl J Med 2009, 360:363-375.

10. Sibbing D, Stegherr J, Latz W, Koch W, Mehilli J, Dörrler K, Morath T, Schömig A, Kastrati A, von Beckerath N: Cytochrome P450 2C19 loss-offunction polymorphism and stent thrombosis following percutaneous coronary intervention. Eur Heart J 2009, 30:916-922.

11. Shuldiner AR, O'Connell JR, Bliden KP, Gandhi A, Ryan K, Horenstein RB, Damcott CM, Pakyz R, Tantry US, Gibson Q, Pollin TI, Post W, Parsa A, Mitchell BD, Faraday N, Herzog W, Gurbel PA: Association of cytochrome P450 2C19 genotype with the antiplatelet effect and clinical efficacy of clopidogrel therapy. JAMA 2009, 302:849-857.

12. Mega JL, Close SL, Wiviott SD, Shen L, Hockett RD, Brandt JT, Walker JR, Antman EM, Macias W, Braunwald E, Sabatine MS: Cytochrome p-450 polymorphisms and response to clopidogrel. N Engl J Med 2009, 360:354-362.

13. Collet JP, Hulot JS, Pena A, Villard E, Esteve JB, Silvain J, Payot L, Brugier D, Cayla G, Beygui F, Bensimon G, Funck-Brentano C, Montalescot G: Cytochrome P450 2C19 polymorphism in young patients treated with clopidogrel after myocardial infarction: a cohort study. Lancet 2009, 373:309-317.

14. Harrison P, Frelinger ALr, Furman MI, Michelson AD: Measuring antiplatelet drug effects in the laboratory. Thromb Res 2007, 120:323-336.

15. Angiolillo DJ, Fernandez-Ortiz A, Bernardo E, Alfonso F, Macaya C, Bass TA, Costa MA: Variability in individual responsiveness to clopidogrel: clinical implications, management, and future perspectives. J Am Coll Cardiol 2007, 49:1505-1516.

16. Bonello L, Bonello-Palot N, Armero S, Bonello C, Mokhtar OA, Arques S, Dignat-George F, Camoin-Jau L, Paganelli F: Impact of P2Y12-ADP receptor polymorphism on the efficacy of clopidogrel dose-adjustment according to platelet reactivity monitoring in coronary artery disease patients. Thromb Res 2010, 125:e167-70.

17. Aleil B, Ravanat C, Cazenave JP, Rochoux G, Heitz A, Gachet C: Flow cytometric analysis of intraplatelet VASP phosphorylation for the detection of clopidogrel resistance in patients with ischemic cardiovascular diseases. J Thromb Haemost 2005, 3:85-92.

18. Gurbel PA, Bliden KP, Tantry US: Effect of clopidogrel with and without eptifibatide on tumor necrosis factor-alpha and C-reactive protein release after elective stenting: results from the CLEAR PLATELETS $1 \mathrm{~b}$ study. J Am Coll Cardiol 2006, 48:2186-2191.

19. Gurbel PA, Bliden KP, Zaman KA, Yoho JA, Hayes KM, Tantry US: Clopidogrel loading with eptifibatide to arrest the reactivity of platelets: results of the Clopidogrel Loading With Eptifibatide to Arrest the Reactivity of Platelets (CLEAR PLATELETS) study. Circulation 2005, 111:1153-1159.

20. Pettersen AA, Seljeflot I, Abdelnoor M, Arnesen H: Unstable angina, stroke, myocardial infarction and death in aspirin non-responders. $A$ 
prospective, randomized trial. The ASCET (ASpirin non-responsiveness and Clopidogrel Endpoint Trial) design. Scand Cardiovasc J 2004, 38:353-356.

21. Schwarz UR, Geiger J, Walter U, Eigenthaler M: Flow cytometry analysis of intracellular VASP phosphorylation for the assessment of activating and inhibitory signal transduction pathways in human platelets-definition and detection of ticlopidine/clopidogrel effects. Thromb Haemost 1999, 82:1145-1152.

22. Bidet A, Jais C, Puymirat E, Coste P, Nurden A, Jakubowski J, Nurden P: VerifyNow and VASP phosphorylation assays give similar results for patients receiving clopidogrel, but they do not always correlate with platelet aggregation. Platelets 2010, 21:94-100

23. Harmsze AM, van Werkum JW, Ten Berg JM, Zwart B, Bouman HJ, Breet NJ, van 't Hof AW, Ruven $\mathrm{HJ}$, Hackeng $\mathrm{CM}$, Klungel $\mathrm{OH}$, de Boer $\mathrm{A}$, Deneer $\mathrm{VH}$ : CYP2C19*2 and CYP2C9*3 alleles are associated with stent thrombosis: a case-control study. Eur Heart J 2010, 31:3046-3053.

24. Lee JM, Park S, Shin DJ, Choi D, Shim CY, Ko YG, Kim JS, Shin ES, Chang CW, Lee JE, Jang Y: Relation of genetic polymorphisms in the cytochrome P450 gene with clopidogrel resistance after drug-eluting stent implantation in Koreans. Am J Cardiol 2009, 104:46-51.

25. Bonello L, Palot-Bonello N, Armero S, Camoin-Jau L, Paganelli F: Impact of loading dose adjustment on platelet reactivity in homozygotes of the $2 \mathrm{C} 192^{*}$ loss of function polymorphism. Int J Cardiol 2010, 145(1):165-166.

26. Bonello L, Armero S, Ait Mokhtar O, Mancini J, Aldebert P, Saut N, Bonello N, Barragan P, Arques S, Giacomoni MP, Bonello-Burignat C, Bartholomei MN, Dignat-George F, Camoin-Jau L, Paganelli F: Clopidogrel loading dose adjustment according to platelet reactivity monitoring in patients carrying the $2 \mathrm{C} 19 * 2$ loss of function polymorphism. J Am Coll Cardiol 2010, 56:1630-1636.

27. Sibbing D, Koch W, Gebhard D, Schuster T, Braun S, Stegherr J, Morath T, Schömig A, von Beckerath N, Kastrati A: Cytochrome 2C19*17 allelic variant, platelet aggregation, bleeding events, and stent thrombosis in clopidogrel-treated patients with coronary stent placement. Circulation 2010, 121:512-518

28. Grove EL, Hvas AM, Mortensen SB, Larsen SB, Kristensen SD: Effect of platelet turnover on whole blood platelet aggregation in patients with coronary artery disease. J Thromb Haemost 2011, 9:185-191.

29. Kim KA, Park PW, Hong SJ, Park JY: The effect of CYP2C19 polymorphism on the pharmacokinetics and pharmacodynamics of clopidogrel: a possible mechanism for clopidogrel resistance. Clin Pharmacol Ther 2008, 84:236-242.

30. Paniccia R, Antonucci E, Gori AM, Marcucci R, Giglioli C, Antoniucci D, Gensini GF, Abbate R, Prisco D: Different methodologies for evaluating the effect of clopidogrel on platelet function in high-risk coronary artery disease patients. J Thromb Haemost 2007, 5:1839-1847.

31. Huber K: Genetic variability in response to clopidogrel therapy: clinical implications. Eur Heart J 2010, 31:2974-2976.

32. Storey RF: Clopidogrel in acute coronary syndrome: to genotype or not? Lancet 2009, 373:276-278

33. Farid NA, Small DS, Payne CD, Jakubowski JA, Brandt JT, Li YG, Ernest CS, Salazar DE, Konkoy CS, Winters KJ: Effect of atorvastatin on the pharmacokinetics and pharmacodynamics of prasugrel and clopidogrel in healthy subjects. Pharmacotherapy 2008, 28:1483-1494.

34. Gilard M, Arnaud B, Cornily JC, Le Gal G, Lacut K, Le Calvez G, Mansourati J, Mottier D, Abgrall JF, Boschat J: Influence of omeprazole on the antiplatelet action of clopidogrel associated with aspirin: the randomized, double-blind OCLA (Omeprazole CLopidogrel Aspirin) study. J Am Coll Cardiol 2008, 51:256-260.

35. Hwang SJ, Jeong YH, Kim IS, Park KS, Kang MK, Koh JS, Park JR, Park Y, Koh EH, Kwak CH, Hwang JY, Kim S: Cytochrome 2C19 polymorphism and response to adjunctive cilostazol versus high maintenance-dose clopidogrel in patients undergoing percutaneous coronary intervention. Circ Cardiovasc Interv 2010, 3:450-459.

36. Lau WC, Gurbel PA, Watkins PB, Neer CJ, Hopp AS, Carville DG, Guyer KE, Tait AR, Bates ER: Contribution of hepatic cytochrome P450 3A4 metabolic activity to the phenomenon of clopidogrel resistance. Circulation 2004, 109:166-171.

37. Lau WC, Gurbel PA: The drug-drug interaction between proton pump inhibitors and clopidogrel. CMAJ 2009, 180:699-700.
38. Siller-Matula JM, Lang I, Christ G, Jilma B: Calcium-channel blockers reduce the antiplatelet effect of clopidogrel. J Am Coll Cardiol 2008, 52:1557-1563.

39. Siller-Matula JM, Spiel AO, Lang IM, Kreiner G, Christ G, Jilma B: Effects of pantoprazole and esomeprazole on platelet inhibition by clopidogrel. Am Heart J 2009, 157:148.e1-148.e5.

40. Gremmel T, Steiner S, Seidinger D, Koppensteiner R, Panzer S, Kopp CW: Calcium-channel blockers decrease clopidogrel-mediated platelet inhibition. Heart 2010, 96:186-189.

41. Ang L, Palakodeti V, Khalid A, Tsimikas S, Idrees Z, Tran P, Clopton P, Zafar N, Bromberg-Marin G, Keramati S, Mahmud E: Elevated plasma fibrinogen and diabetes mellitus are associated with lower inhibition of platelet reactivity with clopidogrel. J Am Coll Cardiol 2008, 52:1052-1059.

42. Angiolillo DJ, Fernandez-Ortiz A, Bernardo E, Barrera Ramirez C, Sabate M, Fernandez C, Hernandez-Antolin R, Escaned J, Alfonso F, Macaya C: Platelet aggregation according to body mass index in patients undergoing coronary stenting: should clopidogrel loading-dose be weight adjusted? J Invasive Cardiol 2004, 16:169-174.

43. Kelly RV, Hsu A, Topol E, Steinhubl S: The influence of body mass index on outcomes and the benefit of antiplatelet therapy following percutaneous coronary intervention. J Invasive Cardiol 2006, 18:115-119.

44. Gremmel T, Steiner S, Seidinger D, Koppensteiner R, Panzer S, Kopp CW: Smoking promotes clopidogrel-mediated platelet inhibition in patients receiving dual antiplatelet therapy. Thromb Res 2009, 124:588-591.

45. Desai NR, Mega JL, Jiang S, Cannon CP, Sabatine MS: Interaction between cigarette smoking and clinical benefit of clopidogrel. J Am Coll Cardiol 2009, 53:1273-1278.

doi:10.1186/1477-9560-9-4

Cite this article as: Pettersen et al:: The influence of CYP $2 \mathrm{C} 19^{*} 2$ polymorphism on platelet function testing during single antiplatelet treatment with clopidogrel. Thrombosis Journal 2011 9:4.

\section{Submit your next manuscript to BioMed Central and take full advantage of:}

- Convenient online submission

- Thorough peer review

- No space constraints or color figure charges

- Immediate publication on acceptance

- Inclusion in PubMed, CAS, Scopus and Google Scholar

- Research which is freely available for redistribution

Submit your manuscript at www.biomedcentral.com/submit
Ciomed Central 